\title{
The Acidosis of Chronic Renal Failure Activates Muscle Proteolysis in Rats by Augmenting Transcription of Genes Encoding Proteins of the ATP-dependent Ubiquitin-Proteasome Pathway
}

\author{
James L. Bailey, Xiaonan Wang, Brian K. England, S. Russ Price, Xiaoyu Ding, and William E. Mitch
}

Department of Medicine, Renal Division, Emory University School of Medicine, Atlanta, Georgia 30322

\begin{abstract}
Chronic renal failure (CRF) is associated with negative nitrogen balance and loss of lean body mass. To identify specific proteolytic pathways activated by $\mathrm{CRF}$, protein degradation was measured in incubated epitrochlearis muscles from CRF and sham-operated, pair-fed rats. CRF stimulated muscle proteolysis, and inhibition of lysosomal and calcium-activated proteases did not eliminate this increase. When ATP production was blocked, proteolysis in CRF muscles fell to the same level as that in control muscles. Increased proteolysis was also prevented by feeding CRF rats sodium bicarbonate, suggesting that activation depends on acidification. Evidence that the ATP-dependent ubiquitinproteasome pathway is stimulated by the acidemia of CRF includes the following findings: (a) An inhibitor of the proteasome eliminated the increase in muscle proteolysis; and (b) there was an increase in mRNAs encoding ubiquitin (324\%) and proteasome subunits C3 (137\%) and C9 (251\%) in muscle. This response involved gene activation since transcription of mRNAs for ubiquitin and the C3 subunit were selectively increased in muscle of CRF rats. We conclude that CRF stimulates muscle proteolysis by activating the ATP-ubiquitin-proteasome-dependent pathway. The mechanism depends on acidification and increased expression of genes encoding components of the system. These responses could contribute to the loss of muscle mass associated with CRF. (J. Clin. Invest. 1996. 97:1447-1453.) Key words: gene transcription • proteasome • ubiquitin • chronic renal failure $\bullet$ protein degradation
\end{abstract}

\section{Introduction}

Increased protein catabolism and negative nitrogen balance are characteristic of chronic renal failure (CRF). Early studies by Coles documented that CRF patients had low serum pro-

Address correspondence to Dr. James L. Bailey, Emory University School of Medicine, Renal Division, Box 19, 1364 Clifton Rd., N.E., Atlanta, GA 30322. Phone: 404-727-2525; FAX: 404-727-3425.

Received for publication 10 July 1995 and accepted in revised form 14 December 1995.

1. Abbreviations used in this paper: $\mathrm{CRF}$, chronic renal failure; EDL, extensor digitorum longus; GAPDH, glyceraldehyde-3 phosphate; SO, sham operated.

J. Clin. Invest.

(C) The American Society for Clinical Investigation, Inc.

0021-9738/96/03/1447/07 \$2.00

Volume 97, Number 6, March 1996, 1447-1453 teins and loss of lean body mass (1). Anthropometric measurements reveal that hemodialysis patients have a reduced muscle mass $(2,3)$, and Williams et al. reported that patients with CRF complicated by metabolic acidosis have increased excretion of 3-methylhistidine (4). They concluded that this represented excessive muscle protein catabolism, resulting in negative nitrogen balance. Despite documentation of the problem in patients, cellular processes causing protein catabolism in $\mathrm{CRF}$ remain poorly understood. In particular, the proteolytic pathways activated by CRF and the signals resulting in activation of protein degradation have not been identified.

In muscle, there are at least four pathways that can degrade proteins: lysosomal, calcium-activated proteases, ATP-dependent, and ATP-independent proteolytic pathways (5). Endocytosed proteins are degraded by lysosomal proteases, whereas calcium-activated proteases seem to be important in certain types of muscular dystrophy and in the response to muscle damage (6-8). The ATP-dependent pathways include the ubiquitin-proteasome system, which degrades abnormal and short-lived proteins (9-12). This pathway involves a soluble, multienzyme system that requires ATP (9). Proteins to be degraded are covalently linked to multiple ubiquitins by a ubiquitin-conjugase complex, and degradation occurs in the $26 \mathrm{~S}$ proteasome complex $(9,10,12)$. Little is known about the ATP-independent proteolytic systems $(5,13)$.

When normal rats were fed $\mathrm{NH}_{4} \mathrm{Cl}$ to induce metabolic acidosis, we found that muscle protein degradation was increased. When muscles from these rats were depleted of ATP, the increase in protein degradation was abolished $(14,15)$. We also found increased levels of mRNAs encoding both ubiquitin and subunits of the proteasome, suggesting that the increase in muscle protein degradation involved the ubiquitin-proteasome pathway. These results obtained in studies of rats fed $\mathrm{NH}_{4} \mathrm{Cl}$ may be relevant to the catabolism associated with $\mathrm{CRF}$ because we have also found that muscle protein degradation is increased in rats with experimental CRF and that adding sodium bicarbonate to their diet eliminated the excess protein breakdown (16). In that study, we did not identify the proteolytic pathway activated by CRF.

Increases in both muscle protein degradation and levels of mRNAs encoding components of the ubiquitin-proteasome pathway have been found in association with other catabolic conditions, including sepsis (17), cancer (18-20), burns (21), starvation, and denervation (22). Consequently, insights into the mechanisms leading to increased mRNAs for components of this pathway could have widespread interest.

The present experiments were designed to explore which proteolytic pathway is activated by CRF as well as the mechanism of activation. In studies of rats after subtotal nephrectomy, we used a pair-feeding strategy to eliminate the influence of variations in dietary protein, which can change protein turnover in muscle $(22,23)$. There was direct evidence that 
CRF stimulates muscle protein degradation by activating the ubiquitin-proteasome system, including up-regulation of expression of genes encoding components of this system.

\section{Methods}

Male Sprague-Dawley rats weighing $50-75 \mathrm{~g}$ obtained from Charles River Laboratories (Raleigh, NC) were housed in temperature-controlled quarters with a 12 -h light-dark cycle. Water and $23 \%$ protein pellets (Purina Animal Chow, Inc., Chicago, IL) were provided ad libitum. Rats, anesthetized with $60 \mathrm{mg}$ ketamine and $12 \mathrm{mg}$ xylazine $/ \mathrm{kg}$ intraperitoneally, underwent a right nephrectomy through a flank incision and were fed ad libitum $8 \%$ protein chow prepared by mixing $36 \%$ ground pellet chow (Agway 2000, Madison, WI) and 64\% dextrin (U.S. Biochem. Corp., Cleveland, OH). 1 wk later, rats were anesthetized and branches of the left renal artery were ligated to produce a $7 / 8$ nephrectomy. After surgery, the rats resumed the $8 \%$ protein diet and were given $0.225 \mathrm{~g} / \mathrm{dl} \mathrm{NaCl}$ to drink. $10 \mathrm{~d}$ later, rats were paired by weight to rats that had their abdomen opened and the kidneys manipulated but not damaged (sham-operated [SO] rats). CRF and SO rats were pair-fed a high protein diet for at least $2 \mathrm{wk}$ before the experiment to induce azotemia and acidosis (16). The diet contained $46 \%$ protein, consisting of $35 \%$ casein (Teklad Premier Laboratory Diets, Madison, WI), 25\% dextrin, and 40\% ground pellet chow. After $5 \mathrm{~d}$ of pair feeding, tail vein blood was assayed for urea concentration (16).

In experiments 1 and 2, CRF and pair-fed SO rats were fasted overnight and anesthetized, and their epitrochlearis muscles were removed to measure protein degradation as tyrosine released during an incubation (see below). In a third experiment, we examined whether tyrosine accumulates in muscle under different incubation conditions because tyrosine accumulation could confound the measurement of protein degradation. CRF and control rats were treated in the same fashion, except that after the incubation, epitrochlearis muscles were frozen in liquid $\mathrm{N}_{2}$ and stored at $-70^{\circ} \mathrm{C}$ until they were homogenized in perchloric acid containing fluorophenylalanine as an internal standard. After neutralization of the clear supernatant with $\mathrm{KHCO}_{3}$, the intracellular content of free tyrosine was measured by HPLC as described (24). In a fourth experiment, CRF rats were randomly assigned to group I (CRF rats fed the high-protein diet and given 0.25 normal saline to drink) or group II (CRF rats pair fed the same diet but with $1.7 \mathrm{~g} \mathrm{NaHCO}_{3} / 100 \mathrm{~g}$ chow and given $0.125 \% \mathrm{NaHCO}_{3}$ to drink). Group III rats were sham operated and pair fed with group I rats. In the fifth experiment, seven CRF and pair-fed SO rats were studied by incubating their muscles with an inhibitor of the proteasome (benzyloxycarbonyl-leucine-leucine-leucinal [MG132], kindly provided by ProScript, Inc., Cambridge, MA).

Epitrochlearis muscle incubations. In experiment 1, epitrochlearis muscles from anesthetized rats were dissected, fixed at resting length on a plastic support, and incubated in KRB with or without inhibitors of lysosomal and calcium-activated proteases $(15,25,26)$. Calciumdependent and lysosomal proteases were inhibited by deleting calcium from the KRB and adding $50 \mu \mathrm{M}$ of trans-epoxysuccinyl-Lleucylamido-(4-guanidino butane), E-64, a potent inhibitor of the calpains, as well as the lysosomal proteases cathepsins $\mathrm{B}, \mathrm{H}$, and $\mathrm{L}$ (26). Lysosomal function was also inhibited by adding $1 \mathrm{mU} / \mathrm{ml}$ insulin, $200 \mu \mathrm{M}$ valine, $170 \mu \mathrm{M}$ leucine, $100 \mu \mathrm{M}$ isoleucine, and $10 \mathrm{mM}$ methylamine $(13,25)$. To measure total protein degradation, $0.5 \mathrm{mM}$ cycloheximide was added because this concentration inhibits protein synthesis in incubated rat muscles (27), thereby preventing reutilization of tyrosine released during degradation of muscle proteins. After preincubation ( $30 \mathrm{~min}$ ), each muscle was transferred to a flask containing fresh media and incubated at $37^{\circ} \mathrm{C}$ for a 2-h experimental period. All flasks were gassed with $95 \% \mathrm{O}_{2} / 5 \% \mathrm{CO}_{2}$ for $3 \mathrm{~min}$ at the beginning of the preincubation and experimental periods. After the experimental period, media samples were collected and TCA (final concentration, $5 \%$ ) was added to precipitate protein. The rate of pro- tein degradation was measured as tyrosine released into the media; tyrosine was measured by fluorometry (28).

In experiment 2, another group of CRF and pair-fed SO rats was studied to assess the contribution of the nonlysosomal, ATP-dependent proteolytic process. Muscles were fixed at resting length and incubated under the conditions described above to block both the lysosomal and calcium-dependent proteolytic systems. The contralateral muscle was incubated under the same conditions but also depleted of ATP (preincubation for $1 \mathrm{~h}$ and then incubation for $2 \mathrm{~h}$ in the same media except that the glucose was replaced by $5 \mathrm{mM} 2$-deoxyglucose, and $0.5 \mathrm{mM}$ DNP was added). These conditions reduced the ATP content in muscle to $<10 \%$ of normal values (unpublished observations). The difference in rates of proteolysis was taken to represent the ATP-dependent component.

To test whether the proteasome is involved in protein catabolism stimulated by CRF, we used a peptidyl aldehyde inhibitor of the proteasome, MG 132. Epitrochlearis muscles from CRF and SO pair-fed rats were incubated in calcium-free $\mathrm{KRB}$, containing $10 \mathrm{mM}$ glucose, $0.5 \mathrm{mM}$ cycloheximide, and MG $132(30 \mu \mathrm{M}$, final concentration $)$ dissolved in DMSO. The contralateral muscle was incubated in the same media containing an equivalent amount of DMSO but no inhibitor. After preincubation in the media for $30 \mathrm{~min}$, the experimental period was $2 \mathrm{~h}$.

RNA isolation and analysis. After removal of the epitrochlearis muscle, the gastrocnemius muscles were removed and immediately freeze-clamped in liquid nitrogen. Hindquarter muscles were studied because they, like the epitrochlearis muscle, contain mixed fibers, and the hindquarter exhibits similar responses in terms of muscle protein turnover (28). Total RNA was isolated using TriReagent (Molecular Research Center, Inc., Cincinnati, OH); the quantity and purity of RNA were assessed by measuring absorption at 260 and $280 \mathrm{~nm}$. RNA was separated by electrophoresis in a $1 \%$ agarose/formaldehyde gel, transferred to Zeta Probe GT Nylon membranes (Bio-Rad Laboratories, Hercules, CA), and cross-linked to the membrane by UV irradiation. Membranes were hybridized sequentially with cDNA probes for human ubiquitin and rat proteasome subunits $\mathrm{C} 2, \mathrm{C} 3, \mathrm{C} 9$, and glyceraldehyde-3 phosphate dehydrogenase (GAPDH) in a solution containing $5 \times$ SSC, $5 \times$ Denhardt's solution $(1 \times=0.02 \%$ Ficoll, $0.02 \%$ polyvinylpyrrolidone, $0.02 \%$ BSA), $7 \%$ SDS, $50 \%$ deionized formamide, $10 \%$ polyethylene glycol, and $50 \mu \mathrm{g} / \mathrm{ml}$ denatured herring testis DNA at $42^{\circ} \mathrm{C}$ overnight. Subsequently, membranes were washed once with $2 \times \mathrm{SSC}, 0.5 \%$ SDS at $42^{\circ} \mathrm{C}$ followed by two washes with $0.2 \times \mathrm{SSC}, 0.5 \% \mathrm{SDS}$ at $65^{\circ} \mathrm{C}$ for $20 \mathrm{~min}$ each. Autoradiographic signals were quantified by densitometry and expressed relative to the corresponding GAPDH mRNA value to correct for variations in RNA loading and transfer. GAPDH mRNA was used because we previously found that mRNA levels in muscle with this model of CRF do not change (29).

Transcription assays. Pair-fed SO and CRF rats (16) were anesthetized, and $\sim 14 \mathrm{~g}$ of leg and back muscles or $5 \mathrm{~g}$ of liver was rapidly removed. Tissues were minced with scissors and homogenized at low speed with a Polytron (Brinkmann Instruments, Inc., Westbury, NY) in an ice-cold lysis buffer composed of $10 \mathrm{mM}$ Hepes, $\mathrm{pH}$ 7.5, $5 \mathrm{mM}$ $\mathrm{KCl}, 10 \mathrm{mM} \mathrm{MgCl}_{2}$, and $5 \mathrm{mM} \beta$-mercaptoethanol. Nuclei were pelleted by centrifugation at $1,000 \mathrm{~g}$ for $8 \mathrm{~min}$ and then resuspended in $2.2 \mathrm{M}$ sucrose. After centrifugation at $80,000 \mathrm{~g}$ for $90 \mathrm{~min}$ at $4^{\circ} \mathrm{C}$, the nuclear pellets were washed in $75 \mathrm{mM}$ Hepes, $\mathrm{pH} 7.5,60 \mathrm{mM} \mathrm{KCl}, 15$ $\mathrm{mM} \mathrm{NaCl}, 0.1 \mathrm{mM}$ EDTA, $0.1 \mathrm{mM}$ EGTA, $0.5 \mathrm{mM}$ DTT, $0.5 \mathrm{mM}$ spermidine, $0.5 \mathrm{mM}$ spermine, and $40 \%$ glycerol. The yield of nuclei using this method was small relative to the tissue used.

Isolated nuclei were incubated at $25^{\circ} \mathrm{C}$ for $30 \mathrm{~min}$ in a buffer containing $60 \mathrm{mM}$ Hepes, $\mathrm{pH} 7.5,55 \mathrm{mM} \mathrm{KCl}, 12 \mathrm{mM} \mathrm{NaCl}, 6.5 \mathrm{mM}$ DTT, $0.08 \mathrm{mM}$ EDTA, $0.08 \mathrm{mM}$ EGTA, $0.4 \mathrm{mM}$ spermine, $0.4 \mathrm{mM}$ spermidine, $5 \mathrm{mM} \mathrm{MgCl}_{2}, 0.6 \mathrm{mM}$ ATP, $0.03 \mathrm{mM} \mathrm{CTP}$, and $0.036 \mathrm{mM}$ GTP, with $40 \mathrm{U}$ RNasin and $250 \mu \mathrm{Ci}\left[\alpha{ }^{3}{ }^{32} \mathrm{P}\right] \mathrm{UTP}(3,000 \mathrm{Ci} / \mathrm{mmol})$. The newly transcribed, ${ }^{32} \mathrm{P}$-labeled RNA was purified using TriReagent and hybridized with cDNA probes ( $2 \mu \mathrm{g}$ each) for rat GAPDH, human $\gamma$-actin, human ubiquitin, and the rat proteasome $\mathrm{C} 3$ subunit im- 
mobilized on a GT nylon membrane (Zeta-Probe; Bio-Rad Laboratories, Hercules, CA). To provide a negative hybridization control, linearized pGEM3zf (Promega, Madison, WI) was also hybridized. Hybridizations were performed in $0.12 \mathrm{M} \mathrm{Na}_{2} \mathrm{HPO}_{4}, 0.25 \mathrm{M} \mathrm{NaCl}, 5 \times$ Denhardt's, $50 \%$ formamide, $10 \%$ SDS, $5 \%$ polyethylene glycol, and $50 \mu \mathrm{g} / \mathrm{ml}$ denatured herring DNA at $55^{\circ} \mathrm{C}$ for $3 \mathrm{~d}$. Subsequently, the membranes were washed sequentially with $2 \times \operatorname{SSPE}(1 \times=0.15 \mathrm{M}$ $\mathrm{NaCl}, 0.01 \mathrm{M} \mathrm{Na}_{2} \mathrm{HPO}_{4}, 0.001 \mathrm{M}$ EDTA) at $60^{\circ} \mathrm{C}, 2 \times \mathrm{SSPE}$ containing $25 \mu \mathrm{g} / \mathrm{ml}$ RNase $A$ at room temperature, and $1 \times \mathrm{SSPE} / 0.1 \%$ SDS at $60^{\circ} \mathrm{C}$ for $30 \mathrm{~min}$ each.

Statistics. Values are presented as mean \pm SEM. We compared results obtained in specific experiments by Student's $t$ test or ANOVA. Our results, like those of other investigators $(17,19)$, reveal variability in rates of muscle protein degradation in different experiments. Presumably, this is related to different degrees of acidemia (see Table I), renal insufficiency for varying periods, and differences in food intake. Although the impact of food intake is minimized because SO rats were pair fed with CRF rats, it is not appropriate to compare results obtained in different experiments, and we only tested for statistical significance within each experimental group.

\section{Results}

During pair feeding, the CRF rats gained weight but at a slightly lower rate than SO rats. In the first experiment, the average weight of the CRF rats at the beginning of pair feeding was $108 \pm 6 \mathrm{~g}$ vs $105 \pm 5 \mathrm{~g}$ for the controls. At the conclusion, the CRF rats weighed $134 \pm 10 \mathrm{~g}$ vs $141 \pm 6 \mathrm{~g}$ for the controls. The average serum urea nitrogen in CRF rats was $140 \pm 14 \mathrm{mg} /$ dl vs $28 \pm 2 \mathrm{mg} / \mathrm{dl}$ in SO rats. The CRF rats fed supplemental $\mathrm{NaHCO}_{3}$ in the fourth experiment had an average weight of $94 \mathrm{~g}$ before pair feeding and gained $15 \mathrm{~g}$ before we measured protein degradation. The average weight of the acidotic CRF rats at the start of pair feeding was $94 \mathrm{~g}$, and they gained an average of $8 \mathrm{~g}$ before we measured muscle protein degradation. The SO pair-fed control rats weighing $113 \mathrm{~g}$ initially had the largest weight gain, $17 \mathrm{~g}$. The mean serum bicarbonate of the acidotic CRF rats was $8 \pm 4 \mathrm{mM}$ vs $25 \pm 3 \mathrm{mM}$ in CRF rats fed $\mathrm{NaHCO}_{3}$ and $24 \pm 2 \mathrm{mM}$ in $\mathrm{SO}$ pair-fed control rats.

Muscle protein degradation in CRF. Previously, we found that protein degradation in perfused hindquarter muscles from fed, acidotic, CRF rats was about twofold higher than in muscles of SO pair-fed rats (16). In the present experiments, the $\mathrm{CRF}$-induced increase in protein degradation (Table I) in incubated epitrochlearis muscles was somewhat less. This variability in rates of muscle protein degradation has been noted by others and points out why it is important to compare values measured in CRF and pair-fed control rats in each experiment $(14,16,19,20,30)$. The rate of protein degradation induced by CRF was still excessive when epitrochlearis muscles were incubated with insulin, amino acids, methylamine, and E-64 to block lysosomal and calcium-activated proteolysis (Table I). ATP depletion eliminated this difference, suggesting that the increase in protein degradation stimulated by CRF involved an ATP-dependent pathway. The content of free tyrosine in muscles incubated with or without inhibitors of proteolytic pathways reveals that the differences in tyrosine release could not be attributed to intracellular accumulation of tyrosine (Table II). In fact, experimental conditions associated with a lower rate of tyrosine release also had lower values of intracellular tyrosine. Specifically, the decreased rate of tyrosine released by ATP-depleted muscle reflects a decrease in protein degradation rather than decreased efflux from the intracellular pool.
Table I. CRF Complicated by Acidemia Increases ATP-dependent Protein Degradation in Muscle

\begin{tabular}{lrcr}
\hline & Control & CRF & Difference \\
\hline Experiment 1 & \multicolumn{3}{c}{ Plasma $\mathrm{HCO}_{3}$} \\
& $22 \pm 1$ & $14 \pm 2^{*}$ \\
& & Protein degradation \\
Basal & $119 \pm 9$ & $174 \pm 11^{\ddagger}$ & $55 \pm 14^{\ddagger}$ \\
No lysosome, no calcium & $92 \pm 6$ & $118 \pm 9^{\ddagger}$ & $26 \pm 11^{*}$ \\
Experiment 2 & & Plasma $\mathrm{HCO}_{3}$ \\
& $25 \pm 1$ & $20 \pm 2^{*}$ & \\
No lysosome, no calcium & $60 \pm 5$ & $84 \pm 8^{\ddagger}$ & $24 \pm 9^{*}$ \\
ATP depletion & $54 \pm 5$ & $64 \pm 2$ & $10 \pm 7$ \\
& & & \\
\hline
\end{tabular}

Values are mean \pm SEM of plamsa bicarbonate concentration $\left(\mathrm{HCO}_{3}\right.$, $\mathrm{mM}$ ) and protein degradation (nmol tyrosine released/g muscle per $\mathrm{h}$ ). In Experiment 1, muscles of six pair-fed CRF and SO control rats were fixed at resting length and incubated in KRB with glucose and cycloheximide to measure the basal rate of protein degradation, and the contralateral muscle was incubated in the same media but with insulin, branched-chain amino acids, methylamine, and E64 to block lysosomal function and calcium-activated proteases. In Experiment 2, muscles of five $\mathrm{CRF}$ and control rats were studied to compare the rates of protein degradation when lysosomal function and calcium-activated proteases were inhibited and when the muscles were incubated with the same media but 2-deoxyglucose was substituted for glucose and DNP was added to deplete ATP (see Methods). ${ }^{*} P<0.05$ compared with values measured in control rats by paired Student's $t$ test; ${ }^{\ddagger} P<0.05$ compared with values measured in control rats by ANVOVA.

Since the cell content of amino acids varies with the amount of dietary protein $(24,31)$, this factor may explain the higher values we obtained in epitrochlearis compared with values Tiao et al. found in extensor digitorum longus (EDL) muscles of rats fasted for $16 \mathrm{~h}$ (17).

Since our earlier study indicated that it was the acidosis of CRF that activated muscle proteolysis (16), we tested whether

Table II. Intracellular Tyrosine in Muscles Following Incubation under Conditions Designed to Isolate Different Proteolytic Pathways

\begin{tabular}{lcc}
\hline \multicolumn{1}{c}{ Incubation conditions } & Control & CRF \\
\hline & \multicolumn{2}{c}{ nmol tyrosine/g } \\
& muscle \\
Basal proteolysis & $183 \pm 12$ & $230 \pm 15^{*}$ \\
No lysosome, no calcium & $105 \pm 12$ & $113 \pm 13$ \\
ATP depletion & $92 \pm 10$ & $81 \pm 14$ \\
MG 132 & $82 \pm 9$ & $76 \pm 5$
\end{tabular}

Values are mean \pm SEM of intracellular tyrosine content (nmol tyrosine/ $\mathrm{g}$ muscle) in muscles of six pairs of CRF and SO pair-fed control rats after incubation in media containing $\mathrm{KRB}$, glucose, and cycloheximide (basal proteolysis) or the same media without calcium but with insulin, branched-chain amino acids, and inhibitors to block lysosomal function and calcium-dependent proteases (see Methods). Muscles from six other pairs of CRF and control rats were studied after incubating in the media with inhibitors of lysosomal function and calcium-activated proteases plus 2-deoxyglucose and DNP to deplete ATP; five pairs of CRF and control rats were used to test the influence of incubating with MG 132 on intracellular tyrosine (see Methods). ${ }^{*} P<0.05$ vs control by $t$ test. 


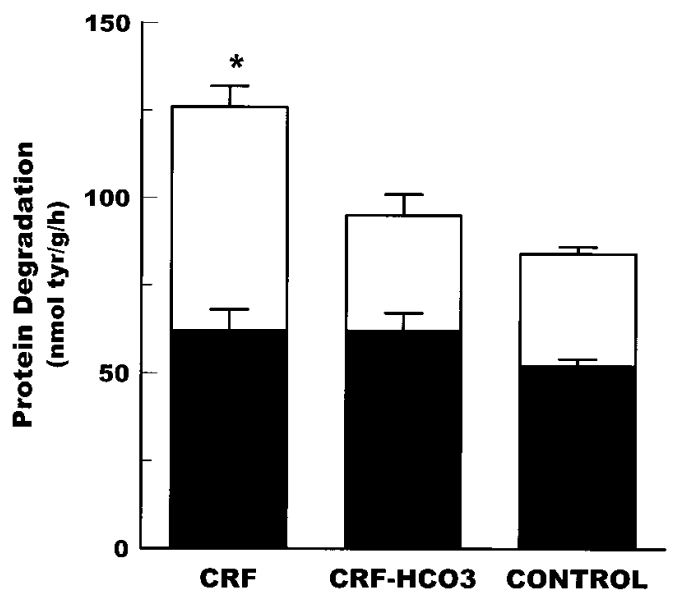

Figure 1. The CRF-induced increase in muscle protein degradation is ATP dependent and is activated by acidification. The increase in protein degradation persists when lysosomal function and calcium-activated proteases are inhibited (full height of bars) but is eliminated when muscles are incubated in the same media but with added 2-deoxyglucose and DNP to deplete ATP (height of darkened bars). By ANOVA, $* P<0.01$ compared with values measured in muscles of SO pair-fed control rats or CRF rats with $\mathrm{NaHCO}_{3}$ in their chow; there were no significant differences in protein degradation measured in ATP-depleted muscles of the three groups of rats.

eliminating acidosis would change the increase in ATP-dependent proteolysis occurring in CRF. For this study, acidotic $\mathrm{CRF}$ rats, $\mathrm{CRF}$ rats fed the $\mathrm{NaHCO}_{3}$ supplement, and pair-fed control rats were compared. Protein degradation was measured in muscles incubated with methylamine and E64 in calcium-free KRB containing cycloheximide, glucose, insulin, and branched-chain amino acids to block lysosomal and calciumactivated proteases, while muscles from the contralateral limb were incubated in the same solution plus 2-deoxyglucose and $0.5 \mathrm{mM}$ DNP but no glucose. In this experiment, proteolysis in

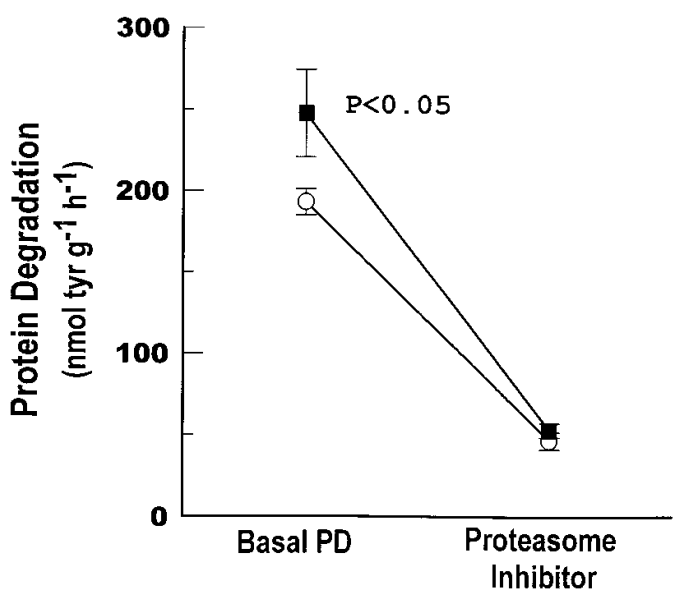

Figure 2. The CRF-induced increase in muscle protein degradation is prevented by an inhibitor of the proteasome. Basal protein degradation was measured in epitrochlearis muscles and compared with values measured in the contralateral muscle incubated with the proteasome inhibitor, MG 132. The difference in protein degradation between CRF and control muscles in the absence of inhibitor was statistically significant by $t$ test $(P<0.05)$; there was no difference when the inhibitor was present. muscles from acidotic CRF rats was higher than in muscles of CRF rats fed $\mathrm{NaHCO}_{3}$ (Fig. 1). The rate of protein degradation in muscles of nonacidotic CRF rats was slightly but not statistically higher than the rate in pair-fed control rats. When ATP production in muscle was blocked, these differences were eliminated.

In a final experiment, MG132, an inhibitor of the proteasome (32), was used to document involvement of the ubiquitin-proteasome pathway in this catabolic response to CRF. In these studies, the mean serum bicarbonate of acidotic CRF rats was $13 \pm 2 \mathrm{mM}$ vs $24 \pm 1 \mathrm{mM}$ for the pair-fed control rats $(P<0.05)$. Again, acidotic $\mathrm{CRF}$ rats had the highest rates of muscle protein degradation, and addition of MG132 eliminated the difference in rates of protein degradation between the two groups (Fig. 2). Elimination of the excessive proteolysis of CRF was not an artifact because of accumulation of tyrosine in the intracellular pool of muscle (Table II), and we found no evidence for toxic effects of MG132 on protein turnover. This conclusion is based on measurements of protein synthesis in the presence of MG 132; protein synthesis $(37.5 \pm 3.8 \mathrm{nmol}$ phenylalanine/g per $\mathrm{h})$ in muscles of seven normal, fasted rats was similar to values we measured previously (28) and did not change significantly $(-6.4 \pm 3.9 \mathrm{nmol}$ phenylalanine/g per $\mathrm{h}$ ) in the contralateral muscle incubated with MG132. We also measured the ATP content in muscles after incubation. It averaged $3.43 \pm 0.32$ in muscles of five control and $3.98 \pm 0.49 \mu \mathrm{mol} / \mathrm{g}$ in muscles of four CRF rats, which is within the range of values measured in epitrochlearis muscle by Nesher et al. (33). By ANOVA, there was no significant difference in the ATP content when MG 132 was present (3.54 \pm 0.66 , control; 2.51 $\pm 0.09 \mu \mathrm{mol} / \mathrm{g}, \mathrm{CRF})$.

Changes in $m R N A$ s of the ubiquitin-proteasome system in $C R F$. The results of hybridizing muscle mRNA with cDNAs for ubiquitin, the $\mathrm{C} 3$ and $\mathrm{C} 9$ subunits of the proteasome, and GAPDH are shown in Fig. 3. Previously, we showed that CRF does not change GAPDH mRNA levels in rat muscle (29), and, after accounting for variations in RNA loading and transfer using GAPDH mRNA levels, we found that CRF induced

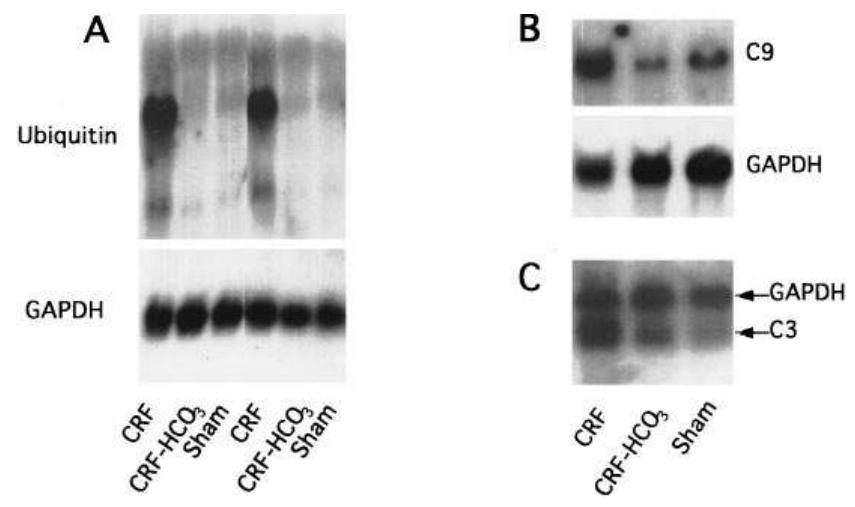

Figure 3. CRF increases levels of ubiquitin and proteasome subunit mRNAs in muscle. Shown are representative autoradiographs from Northern blots of gastrocnemius muscle RNA hybridized with the following: $(A)$ ubiquitin and GAPDH cDNAs; $(B)$ proteasome subunit $\mathrm{C} 9$ and GAPDH cDNAs; and $(C)$ proteasome subunit $\mathrm{C} 3$ and GAPDH cDNAs. Previously, we showed that the ubiquitin cDNA probe used for these studies detects multiple species of polyubiquitin mRNA in muscle (15). 


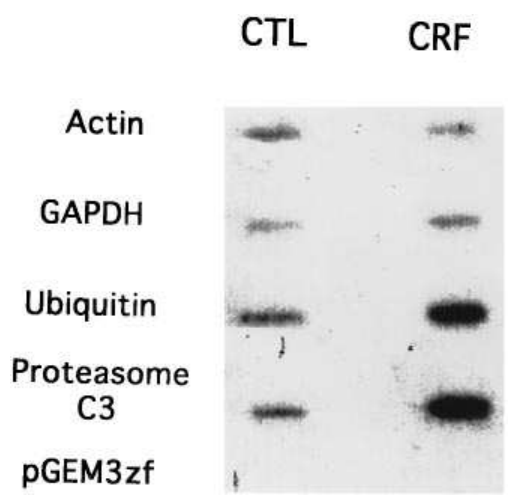

Figure 4. CRF selectively increases transcription of ubiquitin and the $\mathrm{C} 3$ proteasome subunit genes in muscle. Shown are autoradiographic results from nuclear run-on assays performed using nuclei isolated from muscle of one CRF or pair-fed control rat. Transcription of the ubiquitin and proteasome $\mathrm{C} 3$ subunit genes was increased in

CRF rat muscle, but there was no change in the rate of transcription of the $\gamma$-actin or GAPDH genes. pGEM3zf was included as a control for nonspecific hybridization. These results are representative of those obtained from three pairs of $\mathrm{CRF}$ and pair-fed $\mathrm{SO}$ rats.

a $324 \%$ rise in mRNA for ubiquitin ( $n=5$ for each group of rats). There was no increase in ubiquitin mRNA in muscles of CRF rats fed the $\mathrm{NaHCO}_{3}$ supplement (Fig. 3). Similar results were obtained with cDNAs of the proteasome subunits (C3, $137 \%$; C9, 251\%; $P<0.05$ vs control values); we found no increase in mRNA for the $\mathrm{C} 2$ subunit of the proteasome.

To evaluate whether the CRF-induced increase in the levels of mRNAs encoding components of the ubiquitin-proteasome pathway involve an increase in gene transcription, nuclear run-on experiments were performed using nuclei from muscle and liver of CRF or pair-fed control rats. There was no significant difference in the quantity of GAPDH or $\gamma$-actin mRNAs transcribed from nuclei isolated from muscles or livers of CRF and control rats. In contrast, CRF was associated with an increase in transcribed ubiquitin and $\mathrm{C} 3$ proteasome subunit mRNAs in muscle. A representative blot is shown in Fig. 4. In liver, CRF was not associated with an increase in the transcription of GAPDH, $\gamma$-actin, ubiquitin, or C3 genes (data not shown).

\section{Discussion}

Our results provide evidence that the metabolic acidosis of CRF stimulates ATP-dependent proteolysis in muscle and, more specifically, proteolysis involving the proteasome, because the inhibitor of proteasome activity blocked this response. Moreover, metabolic acidosis in CRF is associated with an increase in the muscle content of mRNAs encoding ubiquitin and subunits of the proteasome. These responses were reversed by feeding chow mixed with $\mathrm{NaHCO}_{3}$ to correct the acidosis of CRF, pointing to acidification as a stimulus for these responses. Finally, we investigated the mechanisms for the higher levels of mRNAs encoding components of the ubiquitin-proteasome system and found coordinated increases in transcription of these genes in muscle. It is tempting to speculate that the higher levels of mRNAs encoding elements of this proteolytic system occurring in muscle in other catabolic conditions (e.g., sepsis, cancer, fasting, etc.) also arise from increased transcription, but this has not been shown experimentally. Thus, our results indicate that the metabolic acidosis of CRF activates a specific catabolic pathway in muscle and the transcription of genes encoding components of the pathway.
These responses could compromise the ability of the organism to maintain muscle mass (34).

The first set of experiments included muscles in which lysosomal and calcium-dependent proteolytic pathways were inhibited so the relative contribution of ATP-independent and ATP-dependent proteolytic systems could be evaluated. The decrease in protein degradation associated with inhibition of lysosomal function and calcium-activated proteases was greater in muscles of CRF compared with SO pair-fed rats. By unpaired Student's $t$ test, this difference was not statistically significant, but assessing the contribution of lysosomes and calcium-activated proteases by evaluating differences in proteolytic activity could obscure some influence of CRF on these pathways. However, results in Figs. 1 and 2 and Table I indicate that the major contributor to excess proteolysis is activation of the ATP-ubiquitin-proteasome pathway. Since the residual rates of protein degradation in muscles of CRF and control rats did not differ significantly after inhibition of ATP production, we conclude that CRF stimulates ATP-dependent proteolysis. These results suggest that even a modest degree of acidification in CRF is deleterious because this pathway was stimulated even in CRF rats with an average serum bicarbonate of $20 \mathrm{mM}$.

The initial experiments did not identify which pathway is involved in the accelerated ATP-dependent proteolysis, although our earlier results in acidemic rats suggested it was likely to be the ubiquitin-proteasome system (15). The addition of an inhibitor of proteasome function, MG 132, provides more direct evidence for activation of this system because it eliminated the CRF-induced increase in muscle protein degradation. Like other peptide aldehyde inhibitors, MG 132 readily crosses cell membranes and inhibits the proteolytic activity of both $20 \mathrm{~S}$ and $26 \mathrm{~S}$ proteasomes (the latter form degrades ubiquitin-protein conjugates) $(32,35-37)$. The specificity of the reaction with an inhibitor (including the reaction between MG 132 and the proteasome) is always a potential problem, but this class of compounds has been used to demonstrate that the proteasome is involved in regulating the cell cycle, the processing of the cystic fibrosis transmembrane conductance regulator, and in antigen processing in macrophages (32, 36-38). In muscles from control rats, MG 132 reduced protein degradation sharply, which is consistent with the suggestion that the $20 \mathrm{~S}$ and $26 \mathrm{~S}$ proteasome complexes are responsible for the turnover of the bulk of protein in cells (e.g., normal muscle) (32). The apparent reduction in the rate of protein degradation below the level achieved by ATP depletion could represent degradation in the $20 \mathrm{~S}$ proteasome that can function without ATP since this class of inhibitor will block both the $20 \mathrm{~S}$ and $26 \mathrm{~S}$ form of the proteasome $(32,36,37)$.

Increased levels of mRNAs encoding ubiquitin and components of the proteasome in muscles of CRF acidotic rats compared with pair-fed CRF rats given $\mathrm{NaHCO}_{3}$ or $\mathrm{SO}$ control rats provide additional evidence for activation of the ubiquitin-proteasome pathway (Fig. 3). These responses cannot be attributed to dietary differences, as all groups were pair fed and gained weight (albeit at different rates). Furthermore, gene transcription for ubiquitin and the $\mathrm{C} 3$ proteasome subunit was increased in muscle while that for $\gamma$-actin and GAPDH was unchanged; this was consistent with the CRFinduced changes in mRNAs. Similar changes in gene transcription were not detected in liver from CRF rats, suggesting that this catabolic response appears to be specific for muscle and 
not part of a generalized response to stress. Additional support for this conclusion is given by our finding that muscle DNA and RNA contents are unaltered by CRF (29).

Do these changes in protein degradation, the mRNA levels of ubiquitin and subunits of the proteasome, and gene transcription occur in all types of skeletal muscle? Unfortunately, the amount of muscle and the methods required to measure these responses in the same muscle prevented us from arriving at an easy answer. However, we predict that these changes occur in most types of skeletal muscle for the following reasons: (a) The epitrochlearis muscle we used to measure protein degradation and the gastrocnemius used for RNA analyses contain both red and white types of muscle fiber $(33,39)$, and protein degradation in mixed-fiber muscles responds similarly to fasting and acute uremia $(28,40) ;(b)$ we found that mRNAs of ubiquitin and proteasome subunits in the predominantly white-fiber EDL and mixed-fiber gastrocnemius muscles increase in response to acidemia and glucocorticoids (41); and (c) in response to another catabolic condition, starvation, protein degradation and mRNAs of components of the ubiquitinproteasome system are increased in EDL and in the red-fiber soleus muscle of rats $(30,42)$.

Taken together, our results suggest that the loss of muscle mass associated with CRF is related to up-regulation of the ATP-ubiquitin-proteasome-dependent pathway. What is the signal for these responses? Our previous work suggests that metabolic acidosis in CRF does not cause a sustained alteration in the intracellular $\mathrm{pH}$ of muscle (43). On the other hand, we did find that induction of acidosis by feeding $\mathrm{NH}_{4} \mathrm{Cl}$ to adrenalectomized rats is not sufficient by itself to activate protein degradation or increase mRNAs of the ubiquitin-proteasome pathway in muscle $(14,41)$. In both cases, glucocorticoids must be provided, but the same dose of glucocorticoids given to nonacidotic adrenalectomized rats does not cause these responses. Presumably, glucocorticoids are also involved in the response to $\mathrm{CRF}$ since the steady-state production of corticosterone (measured as its excretion) by CRF rats with or without supplemental $\mathrm{NaHCO}_{3}$ exceeds that of pair-fed control rats (16). Moreover, in CRF patients, Garibotto et al. (44) found a strong positive correlation between muscle protein degradation and plasma levels of cortisol but a negative correlation with serum bicarbonate, suggesting that both acidosis and glucocorticoids are needed to stimulate muscle protein degradation.

In summary, these results provide evidence that CRF activates the ubiquitin-proteasome proteolytic pathway. The primary catabolic stimulus was shown to be a response to acidification rather than the accumulation of other waste products. Several catabolic conditions (e.g., burns, sepsis, cancer, etc.) are associated with increased levels of mRNAs encoding proteins of the ubiquitin-proteasome system. Understanding the mechanisms for activation of the pathway and increased transcription of these genes could lead to more effective therapy for conditions like CRF, which are associated with loss of muscle mass.

\section{Acknowledgments}

These studies were made possible by National Institutes of Health grants T32DK07656 (J.L. Bailey), RO1DK37175 (W.E. Mitch), and P50DK4215 (W.E. Mitch) and a Veteran's Merit Review Grant (B.K. England).

\section{References}

1. Coles, G.A. 1972. Body composition in chronic renal failure. QJM. 41:25-47. 2. Blumenkrantz, M.J., J.D. Kopple, R.A. Gutman, Y.K. Chan, G.L. Barbour, C. Roberts, F.H. Shen, V.C. Gandhi, C.T. Tucker, F.K. Curtis, and J.W. Coburn. 1980. Methods for assessing nutritional status of patients with renal failure. Am. J. Clin. Nutr. 33:1567-1585.

3. Bergstrom, J. 1995. Why are dialysis patients malnourished? Am. J. Kidney Dis. 26:229-241.

4. Williams, B., J. Hattersley, E. Layward, and J. Walls. 1991. Metabolic acidosis and skeletal muscle adaptation to low protein diets in chronic uremia. Kidney Int. 40:779-786.

5. Kettlehut, I.C., S.S. Wing, and A.L. Goldberg. 1988. Endocrine regulation of protein breakdown in skeletal muscle. Diabetes Metab. Rev. 4:751-772.

6. Dice, J.F. 1987. Molecular determinants of protein half-lives in eukaryotic cells. FASEB J. 1:349-357.

7. MacLennon, P.A., A. McArdle, and R.H.T. Edwards. 1991. Effect of calcium on protein turnover of incubated muscles from mdx mice. Am. J. Physiol. 260:E594-E598.

8. Furuno, K., and A.L. Goldberg. 1986. The activation of protein degradation in muscle by calcium or muscle injury does not involve a lysosomal mechanism. Biochem. J. 237:859-864.

9. Hershko, A., and A. Ciechanover. 1992. The ubiquitin system for protein degradation. Annu. Rev. Biochem. 61:761-807.

10. Rechsteiner, M. 1991. Natural substrates of the ubiquitin proteolytic pathway. Cell. 66:615-618.

11. Ciechanover, A., A. Finley, and A. Varshavsky. 1984. Ubiquitin dependence of selective protein degradation demonstrated in the mammalian cell cycle mutant ts85. Cell. 37:57-66.

12. Goldberg, A.L. 1995. Functions of the proteasome: the lysis at the end of the tunnel. Science (Wash. DC). 268:522-524.

13. Gronostajski, R.M., A.B. Pardee, and A.L. Goldberg. 1985. The ATP dependence of the degradation of short- and long-lived proteins in growing fibroblasts. J. Biol. Chem. 260:3344-3349.

14. May, R.C., R.A. Kelly, and W.E. Mitch. 1986. Metabolic acidosis stimulates protein degradation in rat muscle by a glucocorticoid-dependent mechanism. J. Clin. Invest. 77:614-621.

15. Mitch, W.E., R. Medina, S. Greiber, R.C. May, B.K. England, S.R Price, J.L. Bailey, and A.L. Goldberg. 1994. Metabolic acidosis stimulates muscle protein degradation by activating the ATP-dependent pathway involving ubiquitin and proteasomes. J. Clin. Invest. 93:2127-2133.

16. May, R.C., R.A. Kelly, and W.E. Mitch. 1987. Mechanisms for defects in muscle protein metabolism in rats with chronic uremia: the influence of metabolic acidosis. J. Clin. Invest. 79:1099-1103.

17. Tiao, G., J.M. Fagan, N. Samuels, J.H. James, K. Hudson, M. Lieberman, J.E. Fischer, and P. Hasselgren. 1994. Sepsis stimulates nonlysosomal, energy-dependent proteolysis and increases ubiquitin mRNA levels in rat skeletal muscle. J. Clin. Invest. 94:2255-2264.

18. Temparis, S.M., M. Asensi, D. Taillandier, E. Aurousseau, D. Larbaud, A. Obled, D. Bechet, M. Ferrara, J.M. Estrela, and D. Attaix. 1994. Increased ATP-ubiquitin-dependent proteolysis in skeletal muscles of tumor-bearing rats. Cancer Res. 54:5568-5573.

19. Baracos, V.E., C. DeVivo, D.H.R. Hoyle, and A.L. Goldberg. 1995. Activation of the ATP-ubiquitin-proteasome pathway in skeletal muscle of cachectic rats bearing a hepatoma. Am. J. Physiol. 268:E996-E1006.

20. Costelli, P., C. Garcia-Martinez, M. Lovera, N. Carbo, F.J. Lopez-Soriano, N. Agell, L. Tessitore, F.M. Baccino, and J.M. Argiles. 1995. Muscle protein waste in tumor-bearing rats is effectively antagonized by a $\beta_{2}$-adrenergic agonist (clenbuterol): role of the ATP-ubiquitin-dependent proteolytic pathway. J. Clin. Invest. 95:2367-2372.

21. Fang, C., G. Tiao, H. James, C. Ogle, J.E. Fischer, and P. Hasselgren. 1995. Burn injury stimulates multiple proteolytic pathways in skeletal muscle, including the ubiquitin-energy-dependent pathway. J. Am. Coll. Surg. 180:161170

22. Medina, R., S.S. Wing, A. Haas, and A.L. Goldberg. 1991. Activation of the ubiquitin-ATP-dependent proteolytic system in skeletal muscle during fasting and denervation atrophy. Biomed. Biochim. Acta. 50:347-356.

23. Tawa, N.E., I.C. Kettlehut, and A.L. Goldberg. 1992. Dietary protein deficiency reduces lysosomal and nonlysosomal ATP-dependent proteolysis in muscle. Am. J. Physiol. 263:E326-E334.

24. Hara, Y., R.C. May, R.A. Kelly, and W.E. Mitch. 1987. Acidosis, not azotemia, stimulates branched-chain amino acid catabolism in uremic rats. Kidney Int. 32:808-814.

25. Poole, B., and S. Okhuma. 1981. Effect of weak bases on the intralysosomal $\mathrm{pH}$ in mouse peritoneal macrophages. J. Cell Biol. 90:665-669.

26. Hanada, K., M. Tamai, T. Adachi, K. Oguma, K. Kashiwagi, S. Ohmura, E. Kominami, T. Towatari, and N. Katunuma. 1983. Characterization of the three new analogs of E-64 and their therapeutic application. In Proteinase Inhibitors: Medical and Biological Aspects. N. Katunuma, editor. Springer-Verlag, Tokyo. 25-36.

27. Maroni, B.J., R.W. Haesemeyer, M.H. Kutner, and W.E. Mitch. 1990. Kinetics of system A amino acid uptake by muscle: effects of insulin and acute 
uremia. Am. J. Physiol. 258:F1304-F1310.

28. Clark, A.S., and W.E. Mitch. 1983. Comparison of protein synthesis and degradation in incubated and perfused muscle. Biochem. J. 212:649-653.

29. Greiber, S., B.K. England, S.R. Price, R. Medford, R.G. Ebb, and W.E. Mitch. 1994. Na pump defects in chronic uremia cannot be attributed to changes in Na-K-ATPase mRNA or protein. Am. J. Physiol. 266:F536-F542.

30. Wing, S.S., and A.L. Goldberg. 1993. Glucocorticoids activate the ATPubiquitin-dependent proteolytic system in skeletal muscle during fasting. Am. J. Physiol. 264:E668-E676.

31. May, R.C., N. Piepenbrock, R.A. Kelly, and W.E. Mitch. 1991. Leucineinduced amino acid antagonism in rats: muscle valine metabolism and growth impairment. J. Nutr. 121:293-301.

32. Rock, K.L., C. Gramm, L. Rothstein, K. Clark, R. Stein, L. Dick, D. Hwang, and A.L. Goldberg. 1994. Inhibitors of the proteasome block the degradation of most cell proteins and the generation of peptides presented on MHC class 1 molecules. Cell. 78:761-771.

33. Nesher, R., I.E. Karl, K.E. Kaiser, and D.M. Kipnis. 1980. Epitrochlearis muscle. I. Mechanical performance, energetics and fiber composition. Am. J. Physiol. 239:E454-E460.

34. Price, S.R., and W.E. Mitch. 1994. Metabolic acidosis and uremic toxicity: protein and amino acid metabolism. Semi. Nephrol. 14:232-237.

35. Vinitsky, A., C. Cardozo, L. Sepp-Lorenzino, C. Michaud, and M. Orlowski. 1994. Inhibition of the proteolytic activity of the multicatalytic proteinase complex (proteasome) by substrate-related peptidyl aldehydes. J. Biol. Chem. 269:29860-29866.
36. Read, M.A., A.S. Neish, F.W. Luscinskas, V.J. Palombella, T. Maniatis, and T. Collins. 1995. The proteasome pathway is required for cytokine-induced endothelial-leukocyte adhesion molecule expression. Immunity. 2:493-506.

37. Jensen, T.J., M.A. Loo, S. Pind, D.B. Williams, A.L. Goldberg, and J.R. Riordan. 1995. Multiple proteolytic systems, including the proteasome contribute CFTR processing. Cell. 83:129-135.

38. Goldberg, A.L., and K.L. Rock. 1992. Proteolysis, proteasomes and antigen presentation. Nature (Lond.). 357:375-379.

39. Ariano, M.A., R.B. Armstrong, and V.R. Edgerton. 1973. Hindlimb muscle fiber populations of five mammals. J. Histochem. Cytochem. 21:51-55.

40. Clark, A.S., and W.E. Mitch. 1983. Muscle protein turnover and glucose uptake in acutely uremic rat: effects of insulin and the duration of renal insufficiency. J. Clin. Invest. 72:836-845.

41. Price, S.R., B.K. England, J.L. Bailey, K. Van Vreede, and W.E. Mitch. 1994. Acidosis and glucocorticoids concomitantly increase ubiquitin and proteasome subunit mRNAs in rat muscle. Am. J. Physiol. 267:C955-C960.

42. Medina, R., S.S. Wing, and A.L. Goldberg. 1995. Increase in levels of polyubiquitin and proteasome mRNA in skeletal muscle during starvation and denervation atrophy. Biochem. J. 307:631-637.

43. Bailey, J.L., B.K. England, R.C. Long, J. Weisman, and W.E. Mitch 1995. Experimental acidemia and muscle cell $\mathrm{pH}$ in chronic acidosis and renal failure. Am. J. Physiol. (Cell). 269:C706-C712.

44. Garibotto, G., R. Russo, A. Sofia, M.R. Sala, C. Robaudo, P. Moscatelli, G. DeFerrari, and A. Tizianello. 1994. Skeletal muscle protein synthesis and degradation in patients with chronic renal failure. Kidney Int. 45:1432-1439. 